\title{
Worldwide help for survivors of torture
}

\author{
Rosalind RAmSAY, Senior Registrar in Psychiatry, Farnborough Hospital, \\ Farnborough Common, Orpington, Kent BR6 8ND
}

Developments on the world political scene over the last year have had far-reaching effects on the lives of ordinary people in areas such as the Middle East and Eastern Europe. For the International Rehabilitation and Research Centre for Torture Victims (RCT) in Copenhagen these changes have led to a huge increase in calls on its service. In 1991, the continuing opening up of Eastern Europe made it possible to reach out to new countries where support is needed to establish centres offering training in RCT's treatment methods and information about torture, while the Gulf War created more urgent demands on its resources.

Over the last year RCT has intensified its attempts to accumulate and disseminate information about state organised violence, as well as encouraging research and the training of doctors and other relevant professionals in the medical, social, legal and ethical aspects of torture. It supported the launching and running of targeted rehabilitation services in both Denmark and abroad. The international arm of RCT has also maintained its direct financial input to projects in Chile, Greece, Pakistan, the Philippines and Turkey although it was unable to expand its foreign involvement to include work in three other areas-certain African states such as Uganda, Central America and South Africa - all of which are experiencing an acute need with a complete lack of treatment for torture victims.

Following the 1986 conference 'Doctors, Ethics and Torture' another important area of interest for RCT has been the developing of a strategy to prevent and implement sanctions against the participation by doctors in the violation of human rights. As a preliminary target the Danish group has supported schemes to introduce instruction in the field of ethics and human rights for doctors throughout the world. It is also working to protect doctors who are under threat because of their human rights activities and to monitor and expose those who have participated in torture; RCT argues that torture involving the medical profession is especially insidious as at present it is very hard, even if a particular regime falls from power, to obtain definite proof of such activities. All too often a doctor is free to continue his or her professional work without reprimand. In the words of RCT physician Sepp Graessner, "Torture victims suffer from a lifelong lesion of their integrity; co-existence of torturers and victims is unacceptable".

A new way of attracting attention for RCT's work is the short drama-documentary, 'In Spite Of ...', written and directed by 'grande dame' of Danish films, Astrid Henning-Jensen. This short $16 \mathrm{~mm}$ film follows two real 'incidental' torture victims who are granted asylum in Denmark and goes on to show their psychological and physical therapy at the RCT Rehabilitation Centre. During the course of treatment, the psychological sequelae of torture prove more difficult to treat than the physical injuries, but gradually, the therapists at the Centre start to uncover the subjects' deeply buried vivid images of atrocity which were initially revealed only in nightmares. As Botan and Ana re-experience their own torture, in spite of their previous degradation, the two are enabled to find themselves again.

Henning-Jensen expresses her own feelings of social indignation with poetic courage in this portrayal of local prejudice and hostility towards people on the margins of society such as immigrants. Interestingly, she chose not to show any actual torture scenes, explaining, "I only intimate. For example, a victim is blindfolded or hooded. The tramp of boots, getting closer. The glimpse of boots through the blindfold. The screams of people being tortured. Slamming doors. I think that the imagination is strong enough to supply the rest. As one of the participants told me: 'I don't know what was worse. The screams of people being tortured or the torturers' taunting laughter ..." 'In Spite Of ..." has already been shown on Danish television, and is now available to schools, institutions and other organisations in Denmark and abroad as an additional part of RCT's continuing information campaign against torture and in its work to help survivors.

*'In Spite Of ...' (English translation) may be obtained from RCT, Juliane Maries Vej 34, DK-2100 Copenhagen 0, Denmark, telephone 4531394694 . 